\title{
Interaction between adipocytes and high-density lipoprotein:new insights into the mechanism of obesity-induced dyslipidemia and atherosclerosis
}

\author{
Tianhua Zhang ${ }^{\dagger}$, Jin Chen ${ }^{\dagger}$, Xiaoyu Tang, Qin Luo, Danyan Xu and Bilian Yu (D)
}

\begin{abstract}
Obesity is the most common nutritional disorder worldwide and is associated with dyslipidemia and atherosclerotic cardiovascular disease. The hallmark of dyslipidemia in obesity is low high density lipoprotein (HDL) cholesterol $(\mathrm{HDL}-\mathrm{C})$ levels. Moreover, the quality of $\mathrm{HDL}$ is also changed in the obese setting. However, there are still some disputes on the explanations for this phenomenon. There is increasing evidence that adipose tissue, as an energy storage tissue, participates in several metabolism activities, such as hormone secretion and cholesterol efflux. It can influence overall reverse cholesterol transport and plasma HDL-C level. In obesity individuals, the changes in morphology and function of adipose tissue affect plasma HDL-C levels and HDL function, thus, adipose tissue should be the main target for the treatment of HDL metabolism in obesity. In this review, we will summarize the cross-talk between adipocytes and HDL related to cardiovascular disease and focus on the new insights of the potential mechanism underlying obesity and HDL dysfunction.
\end{abstract}

Keywords: Adipocyte, Cholesterol, HDL, Cardiovascular disease, Obesity

\section{Introduction}

Obesity is the most common nutritional disorder worldwide and is one of the major risk factors for atherosclerotic cardiovascular disease (ASCVD) [1]. One of the proatherogenic effects of obesity is attributable to its accompanying dyslipidemia. The prominent dyslipidemia in obesity is low high density lipoprotein (HDL) cholesterol (HDL-C) levels and apolipoprotein A-I (apoA-I). Epidemiological studies have shown a strong inverse correlation between HDL-C, apoA-I and obesity [2, 3]. Specifically, the correlation of low HDL-C with obesity is strongest with central obesity which is characterized by visceral fat deposition $[4,5]$. In addition to low HDLC level, under the state of obesity, cholesterol efflux capacity, nitric oxide-mediated endothelial function, which are the main metrics of HDL function, are impaired in

\footnotetext{
* Correspondence: yubilian@csu.edu.cn

${ }^{\dagger}$ Tianhua Zhang and Jin Chen contributed equally to this work. Department of Cardiovascular Medicine, the Second Xiangya Hospital, Central South University, Changsha, Hunan 410011, People's Republic of China
}

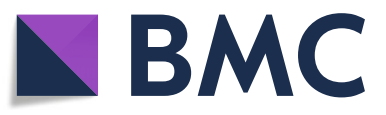

(c) The Author(s). 2019 Open Access This article is distributed under the terms of the Creative Commons Attribution 4.0 International License (http://creativecommons.org/licenses/by/4.0/), which permits unrestricted use, distribution, and reproduction in any medium, provided you give appropriate credit to the original author(s) and the source, provide a link to the Creative Commons license, and indicate if changes were made. The Creative Commons Public Domain Dedication waiver (http://creativecommons.org/publicdomain/zero/1.0/) applies to the data made available in this article, unless otherwise stated. that low HDL-C level is part of the atherogenic dyslipidemia and is strongly and inversely correlated with ASCVD risk. Most importantly, a large number of recent studies have highlighted the possibility that HDL associated metrics other than HDL-C, such as HDL particle concentration, HDL composition, and HDL function are more likely determinants of ASCVD risk [9]. Thus, the mechanisms underlying obesity and HDL alterations are of considerable importance. The overproduction of free fatty acid (FFA) and very low density lipoprotein (VLDL) is regarded as one of the reasons responsible for low HDL-C level [10]. What's more, some key enzymes involved in HDL metabolism, such as cholesteryl ester transfer protein (CETP), lecithin/cholesterol acyltransferase (LCAT), hepatic lipase (HL) and protein phospholipid transfer protein(PLTP), are changed in people with obesity who have insulin resistance [11]. In spite of these interpretations, the mechanisms for the association of obesity and HDL remain to be fully elucidated. 
As we know, adipose tissue is a metabolically dynamic organ, serving as a buffer to control energy metabolism and a regulator of endocrine function related to cardiovascular disease. Abnormal excess energy in obesity leads to hypertrophied adipocytes, which manifest several altered metabolic properties that could play a key role in the obesity-related HDL alterations. Furthermore, recent studies suggested that HDL had reciprocal effect on obesity. In this review, we will focus on the updated understanding of the interaction between adipocytes and HDL, to provide new clues to help us understand the potential mechanism underlying obesity, HDL and atherosclerosis.

\section{HDL metabolism and function, and its relationship with ASCVD}

Reverse cholesterol transport (RCT) is generally thought to be the central antiatherogenic effect of HDL [12]. In the process of RCT, HDL can mediate the removal of cholesterol from peripheral cells and deliver it to the liver for excretion. The first step involves secretion of apoA-I, mainly by the liver and the intestine. Secreted apoA-I interacts functionally with ATP-binding cassette subfamily A member 1 (ABCA1), and this interaction leads to the transfer of cellular phospholipids and cholesterol to lipid-poor apoA-I. The lipidated apoA-I is then gradually converted to disc-shaped particles enriched in unesterified cholesterol. The esterification of free cholesterol by the enzyme LCAT converts the disc-shaped particles to spherical HDL particles, which can further promote cellular cholesterol efflux through ATP-binding cassette transporter G1 (ABCG1) and scavenger receptor class B type I (SR-BI) [13, 14]. As HDL particles get more cholesterol, they engage in the exchange with triglycerides-rich lipoproteins mediated by cholesterol ester transfer protein (CETP). The remaining HDL particles return to the liver, interacting with SR-BI receptor which removes cholesterol for bile acid excretion $[15,16]$. In addition to RCT, HDL also possess several other putative atheroprotective functions, associated to the anti-inflammatory, antithrombotic and anti-oxidant properties as well as to the ability to support endothelial physiology $[17,18]$.

To date, many clinical studies have shown that HDL-C is negatively associated with the risk of ASCVD [19-22]. For a $5 \mathrm{mg} / \mathrm{dl}$ decrement in HDL-C level, there was a $14 \%$ incremental risk of ASCVD events [23]; in contrast, each $1 \mathrm{mg} / \mathrm{dl}$ increase in HDL-C level is associated with a $2-3 \%$ reduction in the risk of ASCVD [24]. However, neither altering HDL-C levels genetically nor raising HDL-C with certain drugs that elevate HDL-C, such as niacin and CETP inhibitors, translates into beneficial cardiovascular outcomes [25-30].

As we know, in human plasma, HDL is a heterogeneous collection of lipoprotein particles ranging in diameter from 7 to $12 \mathrm{~nm}$, and with a density from 1.063 to $1.21 \mathrm{~g} / \mathrm{ml}$ [31]. HDL particles of different sizes contain different amount of cholesterol, and the largest HDL particles contain the most cholesterol [32]. Thus, HDL$C$ levels do not necessarily correlate with HDL particle (HDL-P) concentration, and the increase in HDL-C level is most likely a reflection of a relative increase in HDL particle size $[9,33]$. Furthermore, HDL-C levels are influenced by many different variables that also affect CVD risk, such as sex, smoking, alcohol, diet, aerobic exercise, obesity, type 2 diabetes, and systemic inflammation [34-38]. Whereas, HDL-P levels appear to be correlated to a lesser extent with these factors [39]. Thus, there is growing recognition that cardiovascular risk was better reflected by numbers of lipoprotein particles than by the amount of cholesterol these particles contained [39-41].

Because of the dissociation between improvements in HDL function and HDL-C levels [42, 43], more researches concern the link between HDL function and the incidence of cardiovascular disease. It has been shown that cholesterol efflux capacity, a biomarker that characterizes a key step in RCT, was inversely associated with the incidence of cardiovascular events in a population-based cohort [44]. Many other changes in HDL function, ranging from antioxidant potential to the ability to regulate nitric oxide synthase activity in endothelial cells, have been proposed to be clinically relevant [45]. Taken together, HDL-associated metrics other than HDL-C, such as HDL-P concentration and HDL function, could be more likely determinants of ASCVD risk.

\section{Adipose tissue involved in energy and secretion metabolism related to ASCVD \\ Adipose tissue types and their roles in energy metabolism}

Adipose tissue is the main site for energy storage and is found throughout the body in distinct subcutaneous and visceral depots [46]. According to its morphology, location, and function, adipose tissue can be broadly classified into two main types: white adipose tissue (WAT) and brown adipose tissue (BAT).

In humans, WAT is dispersed throughout the body, with major intra-abdominal depots around the omentum, intestines, and perirenal areas, as well as in subcutaneous depots in the buttocks, thighs, and abdomen [47]. Mature white fat cells contain a single large droplet. The lipid droplets contain a mixture of neutral fats, triglycerides, fatty acids, phospholipids, and cholesterol, in which triglycerides comprise approximately 95\% [48]. As an energy-supplying organ, WAT can release energy through the sequential hydrolysis of triglycerides stored in cell lipid droplets [49]. Apart from storing triglycerides, WAT is also the body's largest free cholesterol 
reservoir [50]. It contains $1-2 \mathrm{mg}$ of cholesterol per gram of wet weight, majority being in the free, unesterified form. In obesity, over half of the total body cholesterol may reside within this tissue [50]. However, WAT is not only a site of cholesterol storage. Recent studies reported that the cholesterol in WAT could efflux to HDL [51], meaning that WAT is also involved in overall cholesterol metabolism.

WAT is not simply an inert storage depot of lipids, but is also an important endocrine organ. It can secrete a number of protein factors that are collectively called adipokines. Adipokines are involved in the regulation of energy intake and balance, in blood pressure regulation, in vascular hemostasis, in lipid metabolism, in carbohydrate homeostasis, and in angiogenesis, as well as growth factors and active phase and stress response proteins. Adipokines are also related to the immune system, including classical cytokines, such as tumor necrosis factor- $\alpha$ (TNF- $\alpha)$, interleukin 6 , and interleukin 8 [52].

BAT, in human fetuses and newborns, is found in axillary, cervical, perirenal, and periadrenal regions, but decreases shortly after birth and has traditionally been considered insignificant in adults [47, 53, 54]. Brown adipocytes are smaller than white adipocytes, their cytoplasm contains several lipid droplets, a roundish nucleus and numerous, large, generally spherical mitochondria with laminar cristae [53]. The multilocality of BAT maximizes the cytoplasmic-lipid interface, making large amounts of fatty acids available quickly for mitochondrial uncoupling and consequent thermogenesis [54]. BAT is an important player in energy expenditure because of its ability to convert energy toward heat using uncoupling protein 1 (UCP1), a process called nonshivering thermogenesis [55]. The high metabolic activity of BAT and adipose tissue browning, referring to the formation of so-called beige adipocytes in WAT [56, 57], suggest that the activation of brown and beige adipocytes may be successfully targeted to combat metabolic and cardiovascular diseases in humans.

Recent research also found evidence of the existence of BAT-derived endocrine factors using BAT transplantation, which led to a significant reduction in body weight gain with increased oxygen consumption and decreased total body fat mass by activating endogenous BAT, resulting in improvement of insulin resistance and liver steatosis $[58,59]$. Acting as a secretory organ, BAT can also release active thyroid hormone triiodothyronine [60], and produces fibroblast growth factor 21 after thermogenic activation [61]. Retinol binding protein-4 is also produced and regulated by BAT [62].

\section{Dysfunctional adipose tissue and atherosclerosis}

In the state of obesity, white adipocyte dysfunction occurs when excess circulating fatty acids flux into adipose tissue exceeds the ability of adipocytes to store the excess energy as triglycerides. Dysfunctional white adipocytes release more fatty acids due to increased basal lipolysis and resistance to insulin. Lipolysis and the subsequent rise in circulating free fatty acid lead to the development of hypertriglyceridemia and insulin resistance in peripheral organs [46]. Additionally, free fatty acid are actively involved in modulating several signalling pathways that mediate inflammation in cells involved in atherosclerosis development [63]. Besides releasing fatty acids, white adipocytes dysfunction is associated with upregulation of inflammatory and apoptotic signalling pathways, endoplasmic reticulum (ER) stress, increased release of pro-inflammatory adipokines and chemokines [64]. In contrast, some adipokines, such as adiponectin and omentin, which have a protective role in atherosclerosis development, are reduced with increased adiposity $[65,66]$. Thus, by inducing dyslipidemia and inflammation, secreting elevated levels of proinflammatory adipokines or reduced levels of antiinflammatory adipokines, WAT participates adversely in the progression of atherosclerosis development in obesity $[67,68]$.

Unlike WAT, BAT has been identified as a key player in triglyceride clearance because thermogenesis of BAT consumes large amounts of fatty acids [69]. Furthermore, BAT activation decreases cholesterol levels as well [70-72]. Thus, BAT is increasingly recognized as a potential therapeutic target to combat atherosclerosis development [73, 74]. Indeed, it has been shown that activating BAT by $\beta 3$-adrenergic receptor stimulation exhibits a protective role from atherosclerosis development in mice [72]. Vice versa, BAT dysfunction generated by knocking out the insulin receptor in BAT specifically in ApoE-/- mice aggravates the atherosclerosis process, characterized by a significant increase of lipid depots, atherosclerotic coverage, lesion size and complexity, increased macrophage infiltration and proinflammatory markers expression [75]. As obesity is a state of low thermogenic adipocyte activity, evidenced by lipid accumulation and mitochondrial dysfunction and loss, i.e."whitening" [76-79], future research might focus on the potential to activate BAT in obese individuals, despite its whitened phenotype.

\section{The HDL: adipocyte connection}

Although macrophage-specific RCT is thought to be the most important mechanism that HDL exerts cardioprotective effects, macrophages have minimal contribution to total cholesterol content in plasma and they don't regulate circulating HDL-C levels [80]. Nowadays, there is increasing evidence that adipose tissue has a potential contribution to HDL metabolism. Considering the large 
area of fat depot, it is tempting to speculate that adipose tissue exerts a great contribution to HDL-C levels.

\section{The cholesterol exchange between adipose tissue and HDL particles: implying a role of adipocytes in HDL-C level}

Adipose tissue is the body's largest cholesterol pool. A particular characteristic of adipocytes is that cholesterol is found mostly in its free, non-esterified form because of lack of acyl-coenzyme A: cholesterol acetyltransferase (ACAT) enzyme activity [81]. This clearly distinguishes the adipocyte from other cell types such as steroidhormone-producing adrenal cells or cholesterol-laden foam cells of atherosclerotic lesions, which have the capacity to accumulate considerable quantities of excess cholesteryl esters (CE) [82]. Previously, adipocytes were considered as the passive cholesterol-buffering sink. In fact, excess free cholesterol is deleterious to cells [83]. Therefore, it is likely that free cholesterol accumulated in adipocytes would export to circulating lipoproteins to maintain cellular cholesterol homeostasis. A decrease in intracellular cholesterol content was associated with an increase in serum lipoprotein cholesterol levels in experimental animals under certain fasting conditions [84-86]. Conversely, diet-induced hypercholesterolemia can lead to an elevation of the adipocyte cholesterol level $[50,87,88]$. These observations suggested that a dynamic equilibrium might exist between serum lipoprotein cholesterol and adipocyte cholesterol pools. Subsequent studies have shown that adipose tissue expresses high levels of key cholesterol transporters ABCA1 and SR-BI [89, 90], providing a gateway for cholesterol to efflux onto apoA-I or HDL particles. Prattes et al. [91] have demonstrated that extracellular cholesterol acceptors $\beta$-cyclodextrin or apoA-I can induce energy-dependent intracellular cholesterol trafficking between lipid droplet and plasma membrane (PM), and then remove cholesterol from PM, raising the possibility that adipocytes have the ability to efflux cholesterol. Based on the above in vitro study, Zhang et al. [51] injected adipocytes labeled with ${ }^{3} \mathrm{H}$-cholesterol into the peritoneal cavity of mice to track ${ }^{3} \mathrm{H}$-cholesterol movement and confirmed that adipocytes are a regulated source of cholesterol transfer to HDL both in vitro and in vivo. In contrast to liver and macrophages, adipocyte cholesterol efflux is controlled by ABCA1 and SR-BI, but not ABCG1.

However, the study was inherently limited in its capacity to accurately determine the amount of cholesterol that was transported to HDL and the potential impact on plasma HDL-C levels. Subsequently, Chung et al. [92] determined the contribution of adipose tissue ABCA1 to HDL biogenesis in vivo by using adipocytespecific ABCA1 knockout mice. Deletion of ABCA1 in adipocytes resulted in their failure to efflux cholesterol to apoA-I and a significant decrease in plasma HDL cholesterol $(\sim 15 \%)$ and apoA-I $(\sim 13 \%)$ concentrations. Little difference in plasma decay of ${ }^{125}$ I-HDL tracer was evident between genotypes, indicating that the reduction of HDL-C was attributable to impaired HDL biogenesis and not to increased clearance. Collectively, these results above establish a novel role for adipocyte in whole-body cholesterol balance and in vivo HDL production.

As a consequence of the low activity in cholesterol synthetic pathway, the majority of adipocyte cholesterol originates from circulating lipoproteins. Thus, in addition to cholesterol efflux from adipocytes to HDL, adipocytes have also developed a dual mechanism to extract cholesterol from HDL in the circulation; one is based on the typical HDL receptor SR-BI, the other is based on a novel "efflux recapture" process that needs apolipoprotein $\mathrm{E}$ and the LDL receptor related protein (LRP) [93-95].

Taken together, through the uptake and efflux pathway, adipocytes establish a communication between the adipose tissue-free cholesterol depot and the blood cholesterol pool, which is in favor of cholesterol homeostasis in general, as well as in the adipocyte. Because adipocyte cholesterol accumulation is associated with triglyceride accretion during adipocyte hypertrophy [96], thus, it is conceivable that impaired adipocyte cholesterol efflux or influx which results in cholesterol retention could damage adipose function. However, a recent study conducted by Cuffe et al. [97] demonstrated that although deletion of ABCA1 in adipocytes results in accumulation of cholesterol within adipose, it can afford adipocytes a protective mechanism to avoid excessive triglycerides accumulation. The reason for the discrepancy may be attribute to the high levels of plasma membrane cholesterol in ABCA1 knockout adipocytes. In contrast, adipocyte cholesterol moves from the plasma membrane to the lipid droplet during hypertrophy, leading to enlarged adipocytes and relative depletion of plasma membrane cholesterol [98].

\section{Adipose tissue can influence HDL-C level by lipolysis}

In addition to cholesterol exchange, WAT lipolysis can also modulate HDL-C levels. Several small cohort studies used different hormones [99-102], such as catecholamines and insulin, to stimulate or inhibit adipocyte lipolysis in patients with familial combined hyperlipidemia and endogenous hypertriglyceridemia to detect changes in serum lipids. These studies showed that there is an association between the HDL-C level and lipolysis. However, in these studies, the subjects were patients with metabolic disorders; therefore, the stimulatory or inhibitory effect by hormones would be attenuated by related changes caused by these disorders. Recently, 
Ryden et al. [103] performed an experiment on 1066 healthy women and men with no other metabolic diseases to examine spontaneous lipolysis and the effects of the major hormones that stimulate and inhibit lipolysis. They found that resistance to the antilipolytic effect of insulin and a high rate of basal lipolysis are associated with low HDL-C and high triglycerides levels. This study further confirmed that lipolysis in subcutaneous fat cells is an important and independent contributor to variations in plasma triglycerides and HDL-C levels. In addition to subcutaneous fat cells, an inverse relationship was also observed between catecholaminestimulated visceral fat cell lipolysis and HDL-C level [104]. Although the lipolytic activity is higher in visceral than the subcutaneous depot [105], subcutaneous WAT, which is the body's largest fat depot, is likely to be a much more important contributor to HDL-C level than visceral fat.

In terms of mechanism, increased lipolysis can affect HDL-C level by both direct and indirect effects. On the one hand, WAT lipolysis can hydrolysis triglycerides and release free fatty acids (FFAs) into the plasma, which can be used for hepatic VLDL assembly and secretion. These triglyceride-rich VLDL particles may reduce HDL-C levels by increasing the transfer of triglycerides to HDL, which in turn are hydrolyzed by hepatic lipase. On the other hand, FFAs could induce insulin resistance [106] and alter CETP activity [107], which have roles inHDL metabolism.

\section{Adipocytes can influence the function of HDL}

Recently, emerging evidence indicates that HDL function other than HDL-C, especially cholesterol efflux and $\mathrm{RCT}$, is a stronger predictor of ASCVD risk. Induction of obesity impairs overall RCT in ob/ob mice raising the possibility that adipocytes can influence the function of HDL [8]. Repeated cryostimulation in humans has been described to lower plasma TG while increasing plasma HDL cholesterol levels; and the expression of UCP1 in human epicardial fat is associated with lower plasma TG and higher plasma HDL-cholesterol levels. Furthermore, it has been shown that the activation of thermogenic adipocytes by $\beta 3$-adrenergic receptor stimulation reduces cholesterol levels and protects from atherosclerosis in transgenic mice expressing both a loss-of-function variant of human apolipoprotein E (APOE*3-Leiden; E3L) and the human CETP (E3L.CETP mice) [72]. These results strongly indicate a role of thermogenic adipocytes in the anti-atherogenic properties of HDL. Zvintzou E et al. [108] showed that APOC3 modulates HDL structure and function, while it selectively promotes BAT metabolic activation. In addition, a recent study conducted by Bartel et al. [77] painstakingly determined that both cold-induced and pharmacological thermogenic adipocytes activation enhance HDL function, which is defined as increased HDL-cholesterol clearance and macrophage-to-faeces RCT. Mechanistically, the authors showed that intravascular lipolysis by adipocyte lipoprotein lipase and hepatic uptake of HDL by SR-BI are the driving forces of HDL-cholesterol disposal in liver. However, further cholesterol efflux experiments from brown and beige adipocytes will be needed to show whether the high lipolytic activity of thermogenic adipocytes not only increases intravascular HDL remodelling and turnover as shown in the above study, but also enhances cholesterol efflux from cells to HDL particles.

\section{The reciprocal effect of HDL/ apoA-I on adipocyte function}

Human adipocytes possess HDL binding sites, which are specific for apoA-I and/or apoA-II, and independent of apoE raising the possibility that HDL might exert reciprocal effect on adipocyte function. Indeed, Van Linthout et al. [109] increased HDL in vivo by human apoA-I gene transfer and supplemented HDL in vitro on partially differentiated adipocytes and subsequently demonstrated that HDL elevates plasma adiponectin concentrations in vivo and increases adiponectin expression in adipocytes in a phosphatidylinositol-3-kinase dependent manner. As adiponectin is an anti-inflammatory adipokine [110], it is likely that the effects of HDL on adiponectin expression may contribute to its anti-inflammatory effects. Recently, Umemoto et al. [111] showed that apoA-I and HDL strongly inhibited palmitate-induced chemotactic factor expression in adipocytes in vitro and that overexpression of human apoA-I led to a reduction of inflammatory gene expression and macrophage accumulation in adipose tissue in mice fed a high-fat diet. These findings further provide evidence that HDL and apoA-I have antiinflammatory effects on adipocytes and adipose tissue, similar to their better-known effects on vascular cells such as macrophages and endothelial cells. In terms of the mechanism, the anti-inflammatory properties of HDL on adipocytes are in association with disruption and removal of cholesterol from lipid rafts, which are regulated by cholesterol transporters such as ABCA1, ABCG1 and SRBI [102]. Serum amyloid A (SAA)-containing dysfunctional HDL has been shown to have reduced ability to facilitate cholesterol efflux [112,113] and thus have loss of the anti-inflammatory properties on adipocytes [114]. However, mechanisms independent of cholesterol efflux to explain these effects of apoA-I and HDL needs to be further determined.

The action of HDL on adipocytes is not limited to cholesterol extraction and anti-inflammatory effects. Considering that HDL favors the release of adiponectin [111], which can increase insulin sensitivity [115], it is of considerable interest to speculate that HDL could 
therefore exert another beneficial effect bymodulating glucose metabolism. Indeed, in a randomized, crossover, double-blind, placebo-controlled study in patients with type 2 diabetes mellitus, reconstituted HDL treatment reduces plasma glucose levels [116]. In terms of the mechanism, it has been reported that apoA-I can be endocytosed into $\mathrm{C} 2 \mathrm{C} 12$ myocytes through a clathrindependent endocytotic process, and a global deletion of apoA-I in mice reduces AMP-activated protein kinase (AMPK) phosphorylation and glucose uptake in skeletal muscle, leading to increased fat content and compromised glucose tolerance $[117,118]$. In addition to myocytes, increased glucose uptake is also observed in 3 T3L1 adipocytes after HDL incubation [119]. Thus, it seems reasonable that HDL modulates glucose metabolism through increasing the ability of the fat and muscle to metabolize glucose.

Furthermore, apoA-I and HDL also contribute to modulating body fat content by controlling the extent of lipolysis via hormone-sensitive lipase phosphorylation (p-HSL) [120]. It has also been demonstrated that apoAI gene overexpression and D-4F treatment lead to significantly increased UCP1 expression in brown adipose tissue and energy expenditure [118]. It is well known that increased expression of UCP1 in brown adipocyte or ectopic expression of UCP1 in mouse or human skeletal muscle and white adipocyte promotes fatty acid oxidation and resistance to obesity. Together, these findings suggest that apoA-I and HDL might have a direct role in the regulation of body weight and are potential pharmacological targets for the treatment of obesity. However, the mechanism underlying the anti-obesity effect of apoA-I remains to be further elucidated.

\section{The connection of HDL and adipocytes: a tight interconnected link between obesity and HDL metabolic disturbance}

Since adipocytes control the levels of HDL as discussed above, why is HDL-C not elevated with obesity because of increased adipose mass and adipose cholesterol in an obese? As we know, obesity is accompanied by a state of chronic, low-grade adipose tissue inflammation. The cross-talk between adipocytes and macrophages accumulated in adipose amplifies the production of proinflammatory cytokines and chemokines by macrophages and adipocytes, leading to insulin resistance and an increased risk of cardiovascular disease [121-124]. A fascinating observation is that inflammatory mediators such as TNF $\alpha$ impair cholesterol efflux from adipocytes to HDL $[125,126]$. In addition to pro-inflammatory adipokines, reduced levels of anti-inflammatory adipokine adiponectin might also contribute to lower HDL-C levels in the state of obesity. Adiponectin is a collagen-like protein that is exclusively synthesized in WAT. It is induced during adipocyte differentiation, and circulates at relatively high concentrations in serum [127]. Crosssectional studies have reported that adiponectin is positively associated with HDL-C and negatively associated with triglycerides, which implied an important role of adiponectin in HDL metabolism [128, 129]. Subsequently, Oku et al. [130] confirmed the relationship between adiponectin and HDL-C levels by using adiponectin knockout mice. Notably, when focusing on the mechanism by which adiponectin regulates the level of HDL-C, researchers found that adiponectin can affect ABCA1 expression and apoA-I synthesis in the liver $[102,103]$, which are essential for HDL assembly. Taking into account adipose inflammation is a hallmark of obesity, it is intriguing to speculate that attenuation of adipocyte-mediated HDL-lipidation and assembly by elevated levels of pro-inflammatory adipokines or reduced levels of anti-inflammatory adipokine adiponectin may directly contribute to lower plasma HDL-C levels in the state of obesity. However, our laboratory observed that the direct effects of inflammation on the cholesterol efflux capacity of adipocytes highly dependent on cytokine concentration [126]. Low levels of TNF- $\alpha$ could increase adipocyte cholesterol efflux within a certain dose range; whereas high concentrations decreased cholesterol efflux from adipocytes. Thus, the notion that inflammation modulate the efflux capacity of adipose tissue and is responsible for the low levels of HDL-C in obesity is somewhat inconclusive and should be further confirmed in obese mice and humans.

It is well-established that the adipose tissue and liver closely coordinate to regulate energy homeostasis in the body through the secretion of metabolically active hormones or metabolites, including fibroblast growth factor 21 (FGF21), adiponectin, uridine, etc. [131, 132]. Because of chronic excessive caloric intake and lack of physical activity,the adipogenic capacity within adipose tissue may falter, which leads to overly hypertrophied adipocytes [133]. The hypertrophic adipocytes release high levels of FFA and its metabolites, which could result in ectopic fat deposition and non-alcoholic fatty liver disease (NAFLD) [134]. Moreover, in the context of obesity, chronic inflammatory state induced by macrophage accumulation in adipose tissue is also associated with aggravated hepatic fibroinflammatory lesions $[135,136]$. In addition to adipose, hepatic ABCA1 is critical in maintaining the circulating HDL-C levels by formation of nascent HDL particles [137]. In the state of NAFLD, hepatic free cholesterol content was significantly increased accompanied by decreased levels of $\mathrm{ABCA} 1$ and ABCG1 protein [138]. Hence, it can be speculated that energy exchange between adipose tissue and liver could be another possible mechanism underlying the low HDL-C levels in obesity. 
Obesity not only affects the levels of HDL-C in plasma, but also has an impact on the functionality of HDL. However, there is no consolidated explanation for the association between obesity and impaired HDL function. Previous study has shown that obesity was associated with decreases in large HDL subclass distribution [139] and impaired conversion of pre- $\beta 1$ to pre- $\beta 2$ HDL [140], which might have some effects on HDL function. In light of recent studies demonstrating the potential of BAT activation in HDL function as mentioned above, and obesity is a state of low thermogenic adipocyte activity [77], it is tempting to speculate that stimulating thermogenic adipocyte activity may protect from cardiovascular disease not only by decreasing remnant lipoproteins levels but also by stimulating HDL-cholesterol flux from atherogenic lesions to the liver for ultimate cholesterol excretion (Fig. 1).

\section{Conclusions}

In conclusion, low level of HDL-C and impaired HDL function are common lipid disorders in the state of obesity and are considered to play an indispensible role

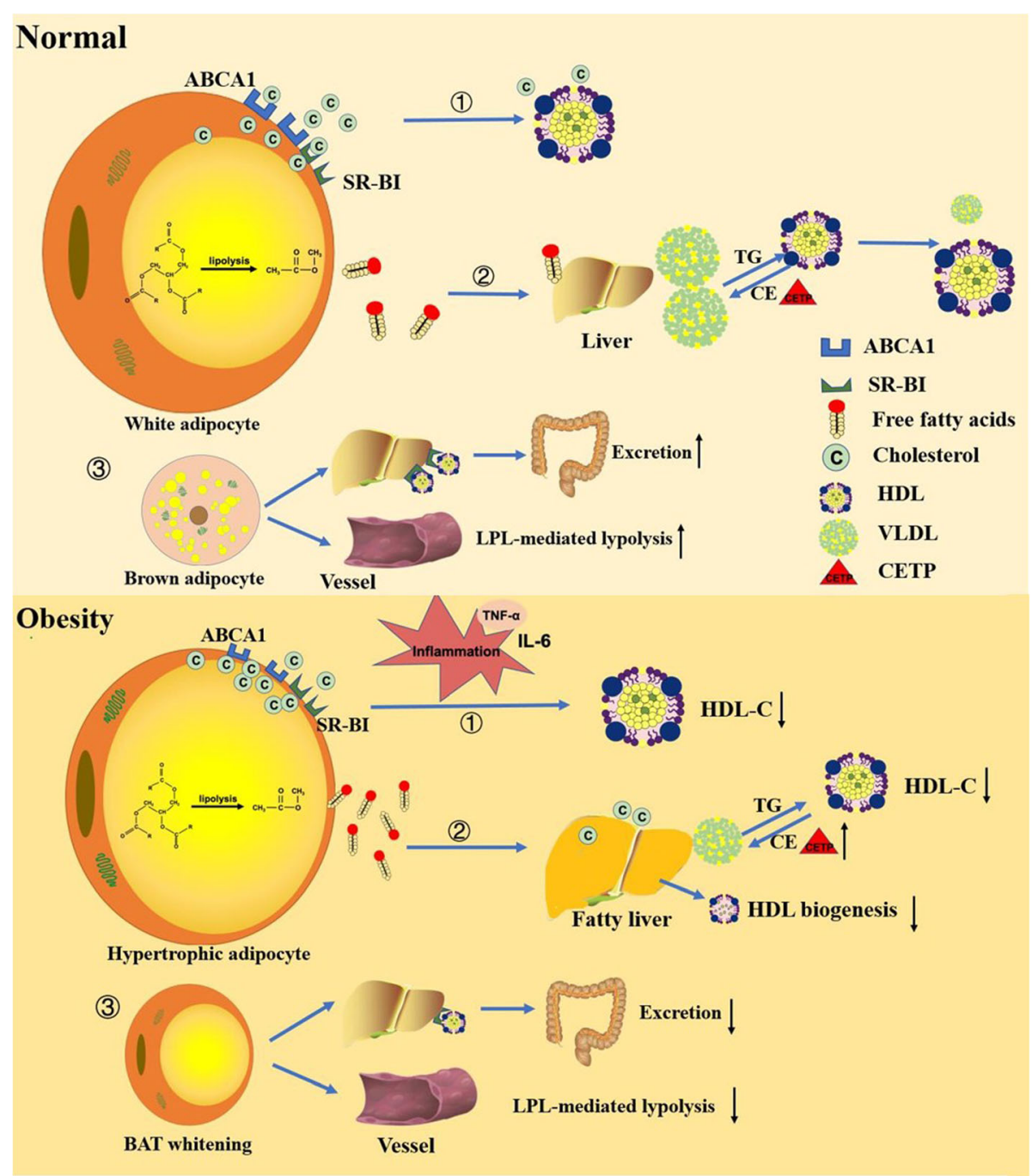

Fig. 1 Under normal condition, adipocytes regulate HDL-C levels and HDL function in three ways. (1)Intracellular cholesterol can efflux to HDL through ABCA1 and SR-BI receptors on the surface of cell membrane to increase HDL-C levels. (2) The free fatty acids released by intracellular triglyceride hydrolysis are used for hepatic production of $\mathrm{VLDL}$, which in turn may reduce $\mathrm{HDL}-\mathrm{C}$ levels by increasing the transfer of triglycerides to HDL. (3) Brown adipocytes mediate HDL-cholesterol clearance and increase macrophage-to-faeces reverse cholesterol transport through intravascular lipolysis by adipocyte lipoprotein lipase and hepatic uptake of HDL by SR-BI. Chronic inflammation, which is the hallmark of obesity, can impair the cholesterol efflux ability of adipocytes, thereby decrease HDL-C levels in plasma. In addition, enhanced lipolysis of adipocytes under the state of obesity releases more free fatty acids into the blood, leading to hypertriglyceridemia and reduced HDL-C levels. FFAs could also induce insulin resistance and alter CETP activity, which have roles in HDL metabolism. The reverse cholesterol transport capacity of HDL might be impaired because of BAT whitening in obesity 
in the development of ASCVD. Considering that adipocytes control the levels and function of HDL, it is intriguing to speculate that the connection between HDL and adipocytes represents the potential mechanism underlying HDL metabolic disturbance in obesity. In normal body weight, adipose tissue can maintain normal cardiovascular function by regulating HDL-C levels and HDL function; while in obese individuals, adipose tissue morphology has been changed, which leading to impaired regulatory function and eventually accelerate the occurrence of cardiovascular disease.

However, there are some questions still need to be further explored. First, the distribution of cholesterol in humans and rodents is different [62, 63, 65, 107], as most of the cholesterol in rodents is carried by HDL particles, whereas most of the cholesterol in human is carried by LDL particles. Thus, the results of the experiments in mice may not be applicable to humans. Second, different WAT locations have different metabolic and endocrine characteristics $[109,141]$. For example, WAT in the breasts and buttocks is highly sensitive to estrogens, while WAT in the upper back and neck is more sensitive to glucocorticoids. Visceral (intra-abdominal) WAT has an adipokine secretion profile related to inflammation and type 2 diabetes, while subcutaneous WAT shows lower amounts of secretion of proinflammatory adipokines [22]. Thus, the results of experiments on tissues from different locations probably should not be compared. In addition, most studies were based on WAT as it is common and easy to obtain; however, the relationship between BAT and HDL needs to be further explored.

\section{Abbreviations \\ ABCA1: ATP-binding cassette sub-family A member 1; ABCG1: ATP-binding cassette transporter G 1; ACAT: Acyl-coenzyme A: cholesterol acetyltransferase; apoA-l: Apolipoprotein A-l; APOE*3-Leiden; E3L: A loss-of- function variant of human apolipoprotein E mice; ASCVD: Atherosclerotic Cardiovascular disease; BAT: Brown adipose tissue; CE: Cholesteryl esters; CETP: Cholesterol ester transfer protein; E3L.CETP: A loss-of-function variant of human CETP mice; ER: Endoplasmic reticulum; FFA: Free fatty acid; FFAs: Free fatty acids; FGF21: fibroblast growth factor 21; HDL: High-density lipoprotein; HDL-C: HDL cholesterol; HDL-P: HDL particle; HL: Hepatic lipase; LCAT: Lecithin/cholesterol acyltransferase; LDL: Low density lipoprotein; LRP: LDL receptor related protein; NAFLD: Non-alcoholic fatty liver disease; $p$ - HSL: Hormone-sensitive lipase phosphorylation; PLTP: Phospholipid transfer protein; PM: Plasma membrane; RCT: Reverse cholesterol transport; SAA: Serum amyloid A; SR-BI: Scavenger receptor class B type 1; TNF- a: Tumor necrosis factor-a; UCP1: Uncoupling protein 1; VLDL: Very low density lipoprotein; WAT: White adipose tissue}

\section{Acknowledgements}

Not applicable.

\section{Authors' contributions}

BY conceived of the scope of the review and designed the manuscript. TZ and JC drafted the manuscript, XT accumulated the relevant references, QL and DX drew the figures. All authors read and approved the final manuscript.

\section{Funding}

This work was supported by a grant from National Natural Science Foundation of China (NSCF), Grant No: 81670420; Natural Science Foundation of Hunan Province of China, Grant No: 2018JJ1045.

\section{Availability of data and materials}

Not applicable.

\section{Ethics approval and consent to participate}

Not applicable.

\section{Consent for publication}

Not applicable.

\section{Competing interests}

The authors declare that they have no competing interests.

Received: 16 February 2019 Accepted: 9 December 2019

Published online: 16 December 2019

\section{References}

1. Moller DE, Kaufman KD. Metabolic syndrome: a clinical and molecular perspective. Annu Rev Med. 2005;56:45-62.

2. Rashid S, Genest J. Effect of obesity on high-density lipoprotein metabolism. Obesity. 2012;15:2875-88.

3. Lamonfava S, Wilson PWF, Schaefer EJ. Impact of body mass index on coronary heart disease risk factors in men and women the Framingham offspring study. Arterioscler Thromb Vasc Biol. 1996;16:1509.

4. Nieves DJ, Cnop M, Retzlaff B, Walden CE, Brunzell JD, Knopp RH, Kahn SE. The atherogenic lipoprotein profile associated with obesity and insulin resistance is largely attributable to intra-abdominal fat. Diabetes. 2003;52: 172.

5. Navarro E, Mijac V, Ryder HF. Ultrasonography measurement of intrabdominal visceral fat in obese men. Association with alterations in serum lipids and insulinemia. Arch Latinoam Nutr. 2010;60:160-7.

6. Sasahara TNP, Fidge N, Sviridov D. Cholesterol transport between cells and high density lipoprotein subfractions from obese and lean subjects. J Lipid Res. 1998:39(3):544.

7. Matsuo Y, Oberbach A, Till H, Inge TH, Wabitsch M, Moss A, Jehmlich N, Völker U, Müller U, Siegfried W. Impaired HDL function in obese adolescents: impact of lifestyle intervention and bariatric surgery. Obesity. 2013;21:E687-95.

8. Calabresi L, Duong M, Uno K, Nankivell V, Bursill C, Nicholls SJ. Induction of obesity impairs reverse cholesterol transport in Ob/Ob mice. PLoS One. 2018;13(9):e0202102.

9. He Y, Kothari V, Bornfeldt KE. High-density lipoprotein function in cardiovascular disease and diabetes mellitus. Arterioscler Thromb Vasc Biol. 2018;38:e10

10. Rashid S, Uffelman KD, Lewis GF. The mechanism of HDL lowering in hypertriglyceridemic, insulin-resistant states. J Diabetes Complicat. 2002;16:24-8.

11. Rashid SGJ. Effect of obesity on high-density lipoprotein metabolism. Obesity (Silver Spring). 2007;15:2875-88.

12. Shah PK, Kaul S, Nilsson J, Cercek B. Exploiting the vascular protective effects of high-density lipoprotein and its apolipoproteins: an idea whose time for testing is coming, part I. Circulation. 2001;104:2498.

13. von Eckardstein A, Kardassis D (Eds.). High density lipoproteins: From biological understanding to clinical exploitation: Springer International Publishing; 2015:53-113.

14. Zhou L, Li C, Gao L, Wang A. High-density lipoprotein synthesis and metabolism (review). Mol Med Rep. 2015;12:4015-21.

15. Ji Y, Wang N, Ramakrishnan R, Sehayek E, Huszar D, Breslow JL, Tall AR. Hepatic scavenger receptor BI promotes rapid clearance of high density lipoprotein free cholesterol and its transport into bile. J Biol Chem. 1999; 274:33398-402.

16. Wang X, Rader DJ. Molecular regulation of macrophage reverse cholesterol transport. Curr Opin Cardiol. 2007;22:368.

17. Prillo A, Catapano AL, Danilo NG. Biological consequences of dysfunctional HDL. Curr Med Chem. 2018;25:1.

18. Furtado JD, Yamamoto R, Melchior JT, Andraski AB, Gamezguerrero M, Mulcahy P, He Z, Cai T, Davidson WS, Sacks FM. Distinct proteomic 
signatures in $16 \mathrm{HDL}$ (high-density lipoprotein) subspecies. Arterioscler Thromb Vasc Biol. 2018:38:2827-42.

19. Collaboration PS, Lewington S, Whitlock G, Clarke R, Sherliker P, Emberson J, Halsey J, Qizilbash N, Peto R, Collins R. Blood cholesterol and vascular mortality by age, sex, and blood pressure: a meta-analysis of individual data from 61 prospective studies with 55,000 vascular deaths. Lancet. 2007;370: 1829-39.

20. Di AE, Sarwar N, Perry P, Kaptoge S, Ray KK, Thompson A, Wood AM, Lewington S, Sattar N. Major lipids, apolipoproteins, and risk of vascular disease. JAMA J Am Med Assoc. 2009;302:1993.

21. Barter P, Gotto AM, Larosa JC, Maroni J, Szarek M, Grundy SM, Kastelein JJ, Bittner V, Fruchart JC. HDL cholesterol, very low levels of LDL cholesterol, and cardiovascular events. N Engl J Med. 2007;357:1301-10.

22. Gordon T, Castelli WP, Hjortland MC, Kannel WB, Dawber TR. High density lipoprotein as a protective factor against coronary heart disease. The Framingham Study. Am J Med. 1977;62:707-14.

23. Gotto AM Jr, Whitney E, Stein EA, Shapiro DR, Clearfield M, Weis S, Jou JY, Langendörfer A, Beere PA, Watson DJ, et al. Relation between baseline and on-treatment lipid parameters and first acute major coronary events in the air force/Texas coronary atherosclerosis prevention study (AFCAPS/ TexCAPS). Circulation. 2000;101:477-84.

24. Jr BH. Increasing HDL cholesterol levels. N Engl J Med. 2004;350:1491-4.

25. Rader DJ, Hovingh GK. HDL and cardiovascular disease. Lancet. 2014;384: 618-25.

26. Rosenson RS. The high-density lipoprotein puzzle. Arterioscler Thromb Vasc Biol. 2016;36:777-82.

27. Zanoni P, Khetarpal SA, Larach DB, Hancockcerutti WF, Millar JS, Cuchel M, Derohannessian S, Kontush A, Surendran P, Saleheen D. Rare variant in scavenger receptor $\mathrm{BI}$ raises $\mathrm{HDL}$ cholesterol and increases risk of coronary heart disease. Science. 2016;351:1166-71.

28. Trigatti BL, Hegele RA. Rare genetic variants and high-density lipoprotein: marching to a different drum. Arterioscler Thromb Vasc Biol. 2016;36(6):e53-5.

29. Rosenson RS. Effects of Dalcetrapib in patients with a recent acute coronary syndrome. N Engl J Med. 2012;367:2089-99.

30. Investigators A, Boden WE, Probstfield JL, Anderson T, Chaitman BR, Desvignes-Nickens P, Koprowicz K, McBride R, Teo K, Weintraub W. Niacin in patients with low HDL cholesterol levels receiving intensive statin therapy. N Engl J Med. 2011;365:2255-67.

31. Wang S, Smith JD. ABCA1 and nascent HDL biogenesis. Biofactors. 2014;40: 547-54.

32. Mendivil CO, Furtado J, Morton AM, Wang L, Sacks FM. Novel pathways of Apolipoprotein A-I metabolism in high-density lipoprotein of different sizes in humans. Arterioscler Thromb Vasc Biol. 2016;36:156-65.

33. Heffron SP, Lin B, Parikh M, Scolaro B, Adelman SJ, Collins HL, Berger JS, Fisher EA. Changes in High-Density Lipoprotein Cholesterol Efflux Capacity After Bariatric Surgery Are Procedure Dependent. Arterioscler Thromb Vasc Biol. 2018;38:245-54.

34. Vergeer M, Holleboom AG, Kastelein JJ, Kuivenhoven JA. The HDL hypothesis: does high-density lipoprotein protect from atherosclerosis? J Lipid Res. 2010;51:2058-73.

35. Tabara Y, Arai H, Hirao Y, Takahashi Y, Setoh K, Kawaguchi T, Kosugi S, Ito Y, Nakayama T, Matsuda F. The causal effects of alcohol on lipoprotein subfraction and triglyceride levels using a Mendelian randomization analysis: the Nagahama study. Atherosclerosis. 2017;257:22-8.

36. Huang S, Li J, Shearer GC, Lichtenstein AH, Zheng X, Wu Y, Jin C, Wu S, Gao $X$. Longitudinal study of alcohol consumption and HDL concentrations: a community-based study. Am J Clin Nutr. 2017;105:905.

37. Rondanelli M, Giacosa A, Morazzoni P, Guido D, Grassi M, Morandi G, Bologna C, Riva A, Allegrini P, Perna S. MediterrAsian diet products that could raise HDL-cholesterol: a systematic review. Biomed Res Int. 2016;2016: 2025687.

38. Ali K, Abo-Ali EM, Kabir MD, Riggins B, Nguy S, Li L, Srivastava U, Thinn SM. A Western-fed diet increases plasma HDL and LDL-cholesterol levels in ApoD-/- mice. PLoS One. 2014;9:e115744.

39. Mackey RH, Greenland P, Goff DC Jr, Lloyd-Jones D, Sibley CT, Mora S. Highdensity lipoprotein cholesterol and particle concentrations, carotid atherosclerosis, and coronary events: MESA (multi-ethnic study of atherosclerosis). J Am Coll Cardiol. 2012;60:508-16.

40. Otvos JD, Collins D, Freedman DS, Shalaurova I, Schaefer EJ, McNamara JR, Bloomfield HE, Robins SJ. Low-density lipoprotein and high-density lipoprotein particle subclasses predict coronary events and are favorably changed by gemfibrozil therapy in the veterans affairs high-density lipoprotein intervention trial. Circulation. 2006;113:1556-63.

41. Mora S, Glynn RJ, Ridker PM. High-density lipoprotein cholesterol, size, particle number, and residual vascular risk after potent statin therapy. Circulation. 2013;128:1189-97.

42. Ray KK, Ditmarsch M, Kallend D, Niesor EJ, Suchankova G, Upmanyu R, Anzurescabrera J, Lehnert V, Paulyevers M, Holme I. The effect of cholesteryl ester transfer protein inhibition on lipids, lipoproteins, and markers of HDL function after an acute coronary syndrome: the dal-ACUTE randomized trial. Eur Heart J. 2014;35:1792-800.

43. Srivastava N, Cefalu AB, Averna M, Srivastava RAK. Lack of correlation of plasma HDL with fecal cholesterol and plasma cholesterol efflux capacity suggests importance of HDL functionality in attenuation of atherosclerosis. Front Physiol. 2018;9:1222.

44. Rohatgi A, Khera A, Berry JD, Givens EG, Ayers CR, Wedin KE, Neeland IJ, Yuhanna IS, Rader DR, De Lemos JA. HDL cholesterol efflux capacity and incident cardiovascular events. N Engl J Med. 2014;371:2383-93.

45. Heinecke JW, Bornfeldt KE. A long road ahead for discovering new HDL metrics that reflect cardiovascular disease risk. J Am Coll Cardiol. 2017;70:179-81.

46. Van Dam AD, Boon MR, Berbee JFP, Rensen PCN, Van Harmelen V. Targeting white, brown and perivascular adipose tissue in atherosclerosis development. Eur J Pharmacol. 2017;816:82-92.

47. Gesta S, Tseng YH, Kahn CR. Developmental origin of fat: tracking obesity to its source. Cell. 2007;131:242-56.

48. Rodriguez A, Ezquerro S, Mendez-Gimenez L, Becerril S, Fruhbeck G. Revisiting the adipocyte: a model for integration of cytokine signaling in the regulation of energy metabolism. Am J Physiol Endocrinol Metab. 2015; 309:E691-714.

49. Bolsoni-Lopes A, Alonso-Vale Ml. Lipolysis and lipases in white adipose tissue - An update. Arch Endocrinol Metab. 2015;59:335-42.

50. Krause BR, Hartman AD. Adipose tissue and cholesterol metabolism. J Lipid Res. 1984;25:97-110.

51. Zhang Y, Mcgillicuddy FC, Hinkle CC, Oneill SM, Glick JM, Rothblat GH, Reilly MP. Adipocyte modulation of high-density lipoprotein cholesterol. Circulation. 2010;121:1347-55.

52. Esteve Rafols M. Adipose tissue: cell heterogeneity and functional diversity. Endocrinol Nutr. 2014;61:100-12.

53. Giordano A, Smorlesi A, Frontini A, Barbatelli G, Cinti S. White, brown and pink adipocytes: the extraordinary plasticity of the adipose organ. Eur J Endocrinol. 2014;170:R159-71.

54. Cannon B, Nedergaard J. Brown adipose tissue: function and physiological significance. Physiol Rev. 2004;84:277-359.

55. van Marken Lichtenbelt WD, Schrauwen P. Implications of nonshivering thermogenesis for energy balance regulation in humans. Am J Phys Regul Integr Comp Phys. 2011;301:R285-96.

56. Bartelt A, Heeren J. Adipose tissue browning and metabolic health. Nat Rev Endocrinol. 2014;10:24-36.

57. Harms M, Seale P. Brown and beige fat: development, function and therapeutic potential. Nat Med. 2013;19:1252-63.

58. Liu X, Wang S, You Y, Meng M, Zheng Z, Dong M, Lin J, Zhao Q, Zhang C, Yuan $X$, et al. Brown adipose tissue transplantation reverses obesity in $\mathrm{Ob} /$ Ob mice. Endocrinology. 2015;156:2461-9.

59. Liu X, Zheng Z, Zhu X, Meng M, Li L, Shen Y, Chi Q, Wang D, Zhang Z, Li C, et al. Brown adipose tissue transplantation improves whole-body energy metabolism. Cell Res. 2013;23:851-4.

60. Villarroya J, Cereijo R, Villarroya F. An endocrine role for brown adipose tissue? Am J Physiol Endocrinol Metab. 2013;305:E567-72.

61. Hondares E, Iglesias R, Giralt A, Gonzalez FJ, Giralt M, Mampel T, Villarroya F. Thermogenic activation induces FGF21 expression and release in brown adipose tissue. J Biol Chem. 2011;286:12983-90.

62. Rosell M, Hondares E, Iwamoto S, Gonzalez FJ, Wabitsch M, Staels B, Olmos Y, Monsalve M, Giralt M, Iglesias R, Villarroya F. Peroxisome proliferatoractivated receptors-alpha and-gamma, and CAMP-mediated pathways, control retinol-binding protein-4 gene expression in brown adipose tissue. Endocrinology. 2012;153:1162-73.

63. Shi H, Kokoeva MV, Inouye K, Tzameli I, Yin H, Flier JS. TLR4 links innate immunity and fatty acid-induced insulin resistance. J Clin Investig. 2006;116:3015-25.

64. Hotamisligil GS. Role of endoplasmic reticulum stress and c-Jun NH2terminal kinase pathways in inflammation and origin of obesity and diabetes. Diabetes. 2005;54:S73. 
65. Okamoto Y, Kihara S, Ouchi N, Nishida M, Arita Y, Kumada M, Ohashi K, Sakai N, Shimomura I, Kobayashi $\mathrm{H}$. Adiponectin reduces atherosclerosis in apolipoprotein E-deficient mice. Circulation. 2002;106:2767-70.

66. Hiramatsuito M, Shibata R, Ohashi K, Uemura Y, Kanemura N, Kambara T, Enomoto T, Yuasa D, Matsuo K, Ito M. Omentin attenuates atherosclerotic lesion formation in apolipoprotein E-deficient mice. Cardiovasc Res. 2016;110:107-117.

67. Ohman MK, Shen Y, Obimba Cl, Wright AP, Warnock M, Lawrence DA, Eitzman DT. Visceral adipose tissue inflammation accelerates atherosclerosis in apolipoprotein E-deficient mice. Circulation. 2008;117:798.

68. Dobrian AD, Hatcher MA, Brotman JJ, Galkina EV, Taghavie-Moghadam P, Pei H, Haynes BA, Nadler JL. STAT4 contributes to adipose tissue inflammation and atherosclerosis. J Endocrinol. 2015;227:13-24.

69. Bartelt A, Bruns OT, Reimer R, Hohenberg H, Ittrich H, Peldschus K, Kaul MG, Tromsdorf UI, Weller H, Waurisch C. Brown adipose tissue activity controls triglyceride clearance. Nat Med. 2011;17:200-5.

70. Geerling JJ, Boon MR, Gc VDZ, Sa VDB, Am VDH, Lombès M, Princen HM, Havekes LM, Rensen PC, Guigas B. Metformin lowers plasma triglycerides by promoting VLDL-triglyceride clearance by brown adipose tissue in mice. Diabetes. 2014;63:880-91.

71. De LF, Mukherjee M, Kadziola Z, Sherwood R, Kakkar W. Central cooling effects in patients with hypercholesterolaemia. Clin Sci. 1998;95:213-7.

72. Berbée JFP, Boon MR, Khedoe PPSJ, Bartelt A, Schlein C, Worthmann A, Kooijman S, Hoeke G, Mol IM, John C. Brown fat activation reduces hypercholesterolaemia and protects from atherosclerosis development. Nat Commun. 2015;6:6356.

73. Hoeke G, Kooijman S, Boon MR, Rensen PCN, Berbée JFP. Role of Brown fat in lipoprotein metabolism and atherosclerosis. Circ Res. 2016;118:173.

74. Xiong W, Zhao X, Villacorta L, Rom O, Garciabarrio MT, Guo Y, Fan Y, Zhu T, Zhang J, Zeng R. Brown adipocyte-specific PPARY (peroxisome proliferatoractivated receptor $\gamma$ ) deletion impairs perivascular adipose tissue development and enhances atherosclerosis in mice. Arterioscler Thromb Vasc Biol. 2018;38:1738-47.

75. Almudena GH, Nuria B, Escribano Ó, Sabela DC, Gema GG, Silvia F, Manuel B. Severe Brown Fat Lipoatrophy Aggravates Atherosclerotic Process in Male Mice. Endocrinology. 2016;157:en20161148.

76. Ouellet V, Labbe SM, Blondin DP, Phoenix S, Guerin B, Haman F, Turcotte EE, Richard D, Carpentier AC. Brown adipose tissue oxidative metabolism contributes to energy expenditure during acute cold exposure in humans. J Clin Invest. 2012;122:545-52.

77. Bartelt A, John C, Schaltenberg N, Berbee JFP, Worthmann A, Cherradi ML, Schlein C, Piepenburg J, Boon MR, Rinninger F, et al. Thermogenic adipocytes promote HDL turnover and reverse cholesterol transport. Nat Commun. 2017:8:15010.

78. van Marken Lichtenbelt WD, Vanhommerig JW, Smulders NM, Drossaerts JM, Kemerink GJ, Bouvy ND, Schrauwen P, Teule GJ. Cold-activated brown adipose tissue in healthy men. N Engl J Med. 2009:360:1500-8.

79. Saito M, Okamatsu-Ogura Y, Matsushita M, Watanabe K, Yoneshiro T, NioKobayashi J, Iwanaga T, Miyagawa M, Kameya T, Nakada K, et al. High incidence of metabolically active brown adipose tissue in healthy adult humans: effects of cold exposure and adiposity. Diabetes. 2009:58:1526-31.

80. Haghpassand M, Bourassa P, Francone O, Aiello R. Monocyte/macrophage expression of $A B C A 1$ has minimal contribution to plasma HDL levels. J Clin Investig. 2001;108:1315-20.

81. Schreibman PH, Dell RB. Human adipocyte cholesterol. Concentration, localization, synthesis, and turnover. J Clin Investig. 1975;55:986-93.

82. Smith FR, Dell RB, Noble RP, Goodman DS. Parameters of the three-pool model of the turnover of plasma cholesterol in normal and hyperlipidemic humans. J Clin Investig. 1976;57:137.

83. Tabas I. Consequences of cellular cholesterol accumulation: basic concepts and physiological implications. J Clin Investig. 2002;110:905-11.

84. Kovanen PT, Nikkila EA, Miettinen TA. Regulation of cholesterol synthesis and storage in fat cells. J Lipid Res. 1975;16:211-23.

85. Krause BR, Balzer M, Hartman AD. Adipocyte cholesterol storage: effect of starvation. Proc Soc Exp Biol Med. 1981;167:407-11.

86. Kraemer FB, Laane C, Park B, Sztalryd C. Low-density lipoprotein receptors in rat adipocytes: regulation with fasting. Am J Phys. 1994;266:E26-32.

87. Smith FR, Dell RB, Noble RP, Goodman DS. Parameters of the three-pool model of the turnover of plasma cholesterol in normal and hyperlipidemic humans. J Clin Invest. 1976;57:137-48.

88. Arner P. Is familial combined hyperlipidaemia a genetic disorder of adipose tissue? Curr Opin Lipidol. 1997:8:89-94.
89. Le LS, Robichon C, Le LX, Dagher G, Ferre P, Dugail I. Regulation of ABCA1 expression and cholesterol efflux during adipose differentiation of 3T3-L1 cells. J Lipid Res. 2003;44:1499.

90. Zhang Y, McGillicuddy FC, Hinkle CC, O'Neill S, Glick JM, Rothblat GH, Reilly MP. Adipocyte modulation of high-density lipoprotein cholesterol. Circulation. 2010;121:1347-55.

91. Prattes S, Horl G, Hammer A, Blaschitz A, Graier WF, Sattler W, Zechner R, Steyrer E. Intracellular distribution and mobilization of unesterified cholesterol in adipocytes: triglyceride droplets are surrounded by cholesterol-rich ER-like surface layer structures. J Cell Sci. 2000;113:2977-89.

92. Chung S, Sawyer JK, Gebre AK, Maeda N, Parks JS. Adipose tissue ATP binding cassette transporter A1 contributes to high-density lipoprotein biogenesis in vivo. Circulation. 2011;124:1663-72.

93. Fazio S, Linton MF. Unique pathway for cholesterol uptake in fat cells. Arterioscler Thromb Vasc Biol. 2004;24:1538.

94. Vassiliou G, Mcpherson R. A novel efflux-recapture process underlies the mechanism of high-density lipoprotein cholesteryl ester-selective uptake mediated by the low-density lipoprotein receptor-related protein. Arterioscler Thromb Vasc Biol. 2004;24:1669-75.

95. Yvancharvet L, Bobard A, Bossard P, Massiera F, Rousset X, Ailhaud G, Teboul $M$, Ferre $P$, Dagher G, Quignard-Boulange A. In vivo evidence for a role of adipose tissue SR-BI in the nutritional and hormonal regulation of adiposity and cholesterol homeostasis. Arterioscler Thromb Vasc Biol. 2007;27:1340-5.

96. Krause BR, Hartman AD. Adipose tissue and cholesterol metabolism. J Lipid Res. 1984:25:97.

97. Cuffe H, Liu M, Key CC, Boudyguina E, Sawyer JK, Weckerle A, Bashore AC, Fried SK, Chung S, Parks JS. Targeted Deletion of Adipocyte Abca1 (ATPBinding Cassette Transporter A1) Impairs Diet-Induced Obesity. Arterioscler Thromb Vasc Biol. 2018;38:733-43.

98. Le LS, Krief S, Farnier C, Lefrère I, Le LX, Bazin R, Ferré P, Dugail I. Cholesterol, a cell size-dependent signal that regulates glucose metabolism and gene expression in adipocytes. J Biol Chem. 2001;276:16904.

99. Larsson B, Bjorntorp P, Holm J, Schersten T, Sjostrom L, Smith U. Adipocyte metabolism in endogenous hypertriglyceridemia. Metabolism. 1975;24: 1375-89.

100. Arner $\mathrm{P}$, Engfeldt $\mathrm{P}$, Ostman J. Changes in the metabolism of fatty acids in adipose tissue in obese patients with primary hypertriacylglycerolemia. J Lipid Res. 1982;23:422-7.

101. Yki-Jarvinen H, Taskinen MR. Interrelationships among insulin's antilipolytic and glucoregulatory effects and plasma triglycerides in nondiabetic and diabetic patients with endogenous hypertriglyceridemia. Diabetes. 1988;37: 1271-8.

102. Reynisdottir S, Eriksson M, Angelin B, Arner P. Impaired activation of adipocyte lipolysis in familial combined hyperlipidemia. J Clin Investig. 1995; 95:2161-9.

103. Ryden M, Arner P. Subcutaneous adipocyte lipolysis contributes to circulating lipid levels. Arterioscler Thromb Vasc Biol. 2017;37:1782-7.

104. Lönnqvist FTA, Large V, Arner P. Sex differences in visceral fat lipolysis and metabolic complications of obesity. Arterioscler Thromb Vasc Biol. 1997; 17(7):1472-80.

105. Lee MJ, Wu Y, Fried SK. Adipose tissue heterogeneity: implication of depot differences in adipose tissue for obesity complications. Mol Asp Med. 2013; $34: 1-11$.

106. Sears B, Perry M. The role of fatty acids in insulin resistance. Lipids Health Dis. 2015;14:121.

107. El HK, Wa VDS, Stroes ES, Kastelein JJ. The role of CETP inhibition in dyslipidemia. Curr Atheroscler Rep. 2007:9:125-33.

108. Zvintzou E, Lhomme M, Chasapi S, Filou S, Theodoropoulos V, Xapapadaki E, Kontush A, Spyroulias GA, Tellis CC, Tselepis AD. Pleiotropic effects of apolipoprotein C3 on HDL functionality and adipose tissue metabolic activity. J Lipid Res. 2017;58:1869-83.

109. Van LS, Forystludwig A, Spillmann F, Peng J, Feng Y, Meloni M, Van CE, Kintscher U, Schultheiss HP, De GB. Impact of HDL on adipose tissue metabolism and adiponectin expression. Atherosclerosis. 2010;210:438-44.

110. Ouchi N, Kihara S, Arita Y, Okamoto Y, Maeda K, Kuriyama H, Hotta K, Nishida M, Takahashi M, Muraguchi M. Adiponectin, an adipocyte-derived plasma protein, inhibits endothelial NF-KB signaling through a CAMPdependent pathway. Circulation. 2000;102:1296-301.

111. Umemoto T, Han CY, Mitra P, Averill MM, Tang C, Goodspeed L, Omer M, Subramanian S, Wang S, Hartigh LJD. Apolipoprotein Al and high-density lipoprotein have anti-inflammatory effects on adipocytes via cholesterol 
transporters ATP-binding cassette A-1, ATP-binding cassette G-1, and scavenger receptor B-1. Circ Res. 2013;112:1345.

112. Artl A, Marsche G, Lestavel S, Sattler W, Malle E. Role of serum amyloid a during metabolism of acute-phase HDL by macrophages. Arterioscler Thromb Vasc Biol. 2000;20:763-72.

113. Vaisar T, Tang C, Babenko I, Hutchins P, Wimberger J, Suffredini AF, Heinecke JW. Inflammatory remodeling of the HDL proteome impairs cholesterol efflux capacity. J Lipid Res. 2015;56:1519-30.

114. Chang YH, Tang C, Guevara ME, Hao W, Wietecha T, Shao B, Subramanian S, Omer M, Wang S, O'Brien KD. Serum amyloid a impairs the antiinflammatory properties of HDL. J Clin Investig. 2015;126:266.

115. Iwabu M, Yamauchi T, Okadalwabu M, Sato K, Nakagawa T, Funata M, Yamaguchi M, Namiki S, Nakayama R, Tabata M. Adiponectin and AdipoR1 regulate PGC-1a and mitochondria by Ca2+ and AMPK/SIRT1. Nature. 2010;464:1313-9.

116. Drew BG, Duffy SJ, Formosa MF, Natoli AK, Henstridge DC, Penfold SA, Thomas WG, Mukhamedova N, de Courten B, Forbes JM, et al. High-density lipoprotein modulates glucose metabolism in patients with type 2 diabetes mellitus. Circulation. 2009;1 19:2103-11.

117. Han R, Lai R, Ding Q, Wang Z, Luo X, Zhang Y, Cui G, He J, Liu W, Chen Y. Apolipoprotein A-I stimulates AMP-activated protein kinase and improves glucose metabolism. Diabetologia. 2007;50:1960-8.

118. Ruan X, Li Z, Zhang Y, Yang L, Pan Y, Wang Z, Feng GS, Chen Y. Apolipoprotein A-I possesses an anti-obesity effect associated with increase of energy expenditure and up-regulation of UCP1 in brown fat. J Cell Mol Med. 2011;15:763-72.

119. Zhang Q, Zhang Y, Feng H, Guo R, Jin L, Wan R, Wang L, Chen C, Li S. High density lipoprotein (HDL) promotes glucose uptake in adipocytes and glycogen synthesis in muscle cells. PLoS One. 2011;6:e23556.

120. Wei H, Averill MM, Mcmillen TS, Dastvan F, Mitra P, Subramanian S, Tang C, Chait A, Leboeuf RC. Modulation of adipose tissue lipolysis and body weight by high-density lipoproteins in mice. Nutr Diabetes. 2014;4:e108.

121. Weisberg SP, Mccann D, Desai M, Rosenbaum M, Leibel RL, Ferrante AW. Obesity is associated with macrophage accumulation in adipose tissue. J Clin Investig. 2003;1 12:1796.

122. Nishimura S, Manabe I, Nagasaki M, Eto K, Yamashita H, Ohsugi M, Otsu M, Hara K, Ueki K, Sugiura S, Yoshimura K, Kadowaki T, Nagai R. CD8+ effector T cells contribute to macrophage recruitment and adipose tissue inflammation in obesity. Nat Med. 2009;15:914

123. Xu H, Barnes GT, Yang Q, Tan G, Yang D, Chou CJ, Sole J, Nichols A, Ross JS, Tartaglia LA. Chronic inflammation in fat plays a crucial role in the development of obesity-related insulin resistance. J Clin Investig. 2003;112: 1821-30.

124. Odegaard Jl, Chawla A. Pleiotropic actions of insulin resistance and inflammation in metabolic homeostasis. Science. 2013;339:172.

125. Mcgillicuddy FC, Reilly MP, Rader DJ. Adipose modulation of high-density lipoprotein cholesterol: implications for obesity, high-density lipoprotein metabolism, and cardiovascular disease. Circulation. 2010;121:1347.

126. Zhao SP, Dong SZ. Effect of tumor necrosis factor alpha on cholesterol efflux in adipocytes. Clin Chim Acta. 2008;389:67-71.

127. Chandran M, Phillips SA, Ciaraldi T, Henry RR. Adiponectin: more than just another fat cell hormone? Diabetes Care. 2003;26:2442-50.

128. Schulze MB, Rimm EB, Shai I, Rifai N, Hu FB. Relationship between adiponectin and glycemic control, blood lipids, and inflammatory markers in men with type 2 diabetes. Diabetes Care. 2004;27:1680-7.

129. Tomono $Y$, Hiraishi $C$, Yoshida H. Age and sex differences in serum adiponectin and its association with lipoprotein fractions. Ann Clin Biochem. 2018;55:165-71.

130. Oku H, Matsuura F, Koseki M, Sandoval JC, Yuasa-Kawase M, TsubakioYamamoto K, Masuda D, Maeda N, Ohama T, Ishigami M, et al. Adiponectin deficiency suppresses ABCA1 expression and ApoA-I synthesis in the liver. FEBS Lett. 2007;581:5029-33.

131. D-w Y, X-I R, Xu A-m, Guo J. liver-adipose tissue crosstalk: a key player in the pathogenesis of glucolipid metabolic disease. Chin J Int Med. 2017;23:410-4.

132. Deng Y, Wang ZV, Gordillo R, An Y, Zhang C, Liang Q, Yoshino J, Cautivo KM, De Brabander J, Elmquist JK, et al. An adipo-biliary-uridine axis that regulates energy homeostasis. Science. 2017;355.

133. Danforth E. Failure of adipocyte differentiation causes type II diabetes mellitus. Nat Genet. 2000;26(1):13-13.

134. Heilbronn LK, Smith SR, Ravussin E. Failure of fat cell proliferation, mitochondrial function and fat oxidation results in ectopic fat storage, insulin resistance and type II diabetes mellitus. Int J Obes. 2004;28.
135. Tordjman J, Guerremillo M, Clement K. Adipose tissue inflammation and liver pathology in human obesity. Diabetes Metab. 2008;34:658-63.

136. Tordjman J, Poitou C, Hugol D, Bouillot J, Basdevant A, Bedossa P, Guerremillo M, Clement K. Association between omental adipose tissue macrophages and liver histopathology in morbid obesity: influence of glycemic status. J Hepatol. 2009;51:354-62.

137. Singaraja RR, Van EM, Bissada N, Zimetti F, Collins HL, Hildebrand RB, Hayden A, Brunham LR, Kang MH, Fruchart JC. Both hepatic and extrahepatic ABCA1 have discrete and essential functions in the maintenance of plasma high-density lipoprotein cholesterol levels in vivo. Circulation. 2006;114:1301-9.

138. Vega-Badillo J, Gutiérrez-Vidal R, Hernández-Pérez HA, Villamil-Ramírez $H$, León-Mimila P, Sánchez-Muñoz F, Morán-Ramos S, Larrieta-Carrasco E, Fernández-Silva I, Méndez-Sánchez N. Hepatic miR-33a/miR-144 and their target gene ABCA1 are associated with steatohepatitis in morbidly obese subjects. Liver Int. 2016;36:1383-91.

139. Woudberg NJ, Goedecke JH, Blackhurst D, Frias M, James R, Opie LH, Lecour S. Association between ethnicity and obesity with high-density lipoprotein (HDL) function and subclass distribution. Lipids Health Dis. 2016;15:92.

140. Sasahara T, Yamashita T, Sviridov D, Fidge N, Nestel P. Altered properties of high density lipoprotein subfractions in obese subjects. J Lipid Res. 1997;38: 600-11.

141. Fong BS, Rodrigues PO, Salter AM, Yip BP, Despres JP, Angel A, Gregg RE. Characterization of high density lipoprotein binding to human adipocyte plasma membranes. J Clin Investig. 1985;75:1804-12.

\section{Publisher's Note}

Springer Nature remains neutral with regard to jurisdictional claims in published maps and institutional affiliations.
Ready to submit your research? Choose BMC and benefit from:

- fast, convenient online submission

- thorough peer review by experienced researchers in your field

- rapid publication on acceptance

- support for research data, including large and complex data types

- gold Open Access which fosters wider collaboration and increased citations

- maximum visibility for your research: over $100 \mathrm{M}$ website views per year

At BMC, research is always in progress.

Learn more biomedcentral.com/submissions 